\title{
EFEITO DA ETAPA DE CENTRIFUGAÇÃO NO TAMANHO DE NANOCRISTAIS DE CELULOSE
}

\author{
D. S. SOARES ${ }^{1}$, F. P. MARTINS ${ }^{1}$, G. A. PUIATTI ${ }^{1}$, R. A. AMARAL ${ }^{1}$, R. L. TEMOTEO ${ }^{1}$, T. \\ G. CARMO ${ }^{1}$, V. K. C. GERMANO ${ }^{1}$, D. J. SILVA ${ }^{1}$, A. V. N. C. TEIXEIRA ${ }^{2}$ \\ Universidade Federal de Viçosa, ${ }^{1}$ Departamento de Química e \\ ${ }^{2}$ Departamento de Física. \\ E-mail: diego.s.soares@ufv.br
}

\begin{abstract}
RESUMO: Investigou-se, utilizando a técnica de espalhamento dinâmico de luz depolarizado, a relação das propriedades dinâmicas de suspensões de nanocristais de celulose (NCC) com a força $G$ de centrifugação aplicada no processo de purificação das mesmas. Amostras contendo NCC foram preparadas por meio de hidrólise com ácido sulfúrico e centrifugadas nas intensidades de 1840, 4140, 7370, 11510 e 16580 de força $G$. Determinou-se os coeficientes de difusão translacionais e rotacionais e, a partir destes, calculou-se as larguras (d) e os comprimentos (L) dos NCC. Os valores de $L$ e de d encontraram-se nas faixas de $213 \pm 10$ a $294 \pm 14 \mathrm{~nm}$ e de 4,4 $\pm 1,2$ a 9,5 \pm 2,0nm, respectivamente. Os resultados concordaram com os disponiveis na literatura, confirmando a aplicabilidade da técnica no estudo da dinâmica dos NCC em suspensões aquosas. Não observou-se variação significativa de $L$ com o aumento da força $G$ na faixa estudada. Por outro lado, houve redução de d para valores de força $G$ acima de 7370.
\end{abstract}

PALAVRAS-CHAVE: Nanocristais de Celulose; Centrifugação; Força G; Espalhamento Dinâmico de Luz; Caracterização de Nanoestruturas.

\section{INTRODUÇÃ̃O}

A busca por novos materiais consiste em utilizar processos mais limpos com utilização de matérias-primas de fontes renováveis que não sejam agressivos ao meio ambiente e ao mesmo tempo que não perca o desempenho de suas propriedades físicas e químicas. Nanocristais de celulose, também conhecidos como whiskers, são os domínios cristalinos de fontes celulósicas e podem ser utilizados para a preparação de bionanocompósitos e carbonos nanoestruturados para aplicações tecnológicas e ambientais, objetivando a melhoria das propriedades mecânicas, ópticas e dielétricas dos materiais. As dimensões dos nanocristais de celulose podem variar em função do material de origem e também da metodologia empregada para obtenção dos mesmos.

Na Tabela 1 são apresentados trabalhos da literatura com as dimensões de nanocristais de celulose para fibras de algodão e as respectivas técnicas de caracterização utilizadas. 
Tabela 1. Trabalhos da literatura que envolvem dimensões de NCC de fibras de algodão.

\begin{tabular}{cccc}
\hline $\begin{array}{c}\text { Técnica de } \\
\text { caracterização }\end{array}$ & $\begin{array}{c}\text { Comprimento } \\
(\mathbf{n m})\end{array}$ & $\begin{array}{c}\text { Largura } \\
(\mathbf{n m})\end{array}$ & Referência \\
\hline Microscopia & $105-141$ & $21-27$ & Elazzouzi-Hafraouiet al. (2008) \\
\hline DLS & $100-300$ & $8-10$ & Souza Lima e Borsali (2004) \\
\hline Microscopia & $100-150$ & $5-10$ & Araki e Kuga (2001) \\
\hline Microscopia & $70-170$ & 7 & Donget al. (1996) \\
\hline Microscopia & $200-300$ & 8 & Heux, Chauve e Bonini (2000) \\
\hline DLS & 255 & 15 & De Souza et al. (2002) \\
\hline Microscopia & $150-210$ & $5-11$ & Miller e Donald (2003)
\end{tabular}

Para a obtenção dos nanocristais, os materiais lignocelulósicos são submetidos a uma etapa prévia de purificação para remoção dos extrativos, da lignina e das hemiceluloses, através de extração com solventes, deslignificação e branqueamento, respectivamente. Os materiais purificados são então submetidos a uma hidrólise ácida, a qual pode ser feita utilizando ácido sulfúrico, em diferentes condições de tempo e de temperatura de reação. Após esta etapa, a reação de hidrólise é interrompida com a adição de água gelada e os materiais são centrifugados para remover o excesso de ácido sulfúrico e, ao mesmo tempo, promover a suspensão dos nanocristais. A razão de aspecto $(L / d)$ dos NCC é um parâmetro que influencia sua habilidade como material de reforço quando incorporada em uma matriz polimérica. Rosa (2012) isolou nanocristais de soja através da centrifugação com $3000 \mathrm{rpm}$ por 30 minutos e obteve-se uma razão de aspecto $(L / d \sim 18)$ através de microscopia eletrônica de transmissão (MET). No trabalho de Neto (2012), os nanocristais de soja foram submetidos à centrifugação por 10 minutos em $7000 \mathrm{rpm}$ e a razão de aspecto obtida por MET para $\mathrm{NCC}_{40}$ foi de 23,5. Em ambos os trabalhos, pode-se observar que a razão de aspecto foi maior que 10, valor mínimo considerado para que ocorra uma transferência de reforço significativa das partículas para a matriz (AZEREDO et al., 2009). Por outro lado, houve uma diferença significativa entre os valores obtidos com a alteração da metodologia para a etapa de centrifugação. Após esta etapa, os whiskers foram dispersos, sonicados em $\mathrm{pH}$ neutro e depois foram armazenados em temperatura próxima de zero grau centígrado.

Como os nanocristais de celulose apresentam potencial para serem utilizados em muitos setores industriais, como embalagens, alimentos, construção, entre outros, pesquisas nessa área têm ganhado amplo destaque no mercado. Dessa forma, trabalhos que utilizaram a técnica de microscopia eletrônica de varredura para caracterizar a morfologia da superfície dos NCC e a análise termogravimétrica para estudo da estabilidade térmica dos NCC, buscam uma maneira rápida, precisa e de baixo custo para determinar o tamanho de nanocristais de celulose (LENG, 2016).

Um dos fatores de destaque em se tratando de celulose é a fonte da matéria-prima. Termo amplamente discutido e pesquisado, essas fontes podem fornecer celulose de 
diferentes estruturas cristalinas e, consequentemente, possuírem características mais ou menos positivas, como, por exemplo, a degradação térmica. Por características próprias de cada fonte, modelos cinéticos de degradação foram criados com a finalidade de demonstrar quais estruturas foram as mais indicadas para determinadas finalidades (HENRIQUE, 2014).

O aperfeiçoamento das partículas de nanocristais de celulose é outro item relevante em pesquisas relacionadas ao tema, incluindo o presente trabalho. Assim como Bai et al. (2009) encontraram em seu trabalho que a força $\mathrm{G}$ é inversamente proporcional aos tamanhos das nanocristais, este trabalho estudou se há dependência entre a força $\mathrm{G}$, ao centrifugar amostras de suspensão de NCC, e os valores dos tamanhos das partículas, variando a frequência de rotação da centrífuga para um determinado tempo. É pertinente salientar a importância de estudos de produção de nanocristais de celulose com tamanhos específicos ou de seleção das dimensões desses durante seu processo de purificação. Fraschini et al. (2014) reportaram que, como já se iniciou a produção industrial de NCC com uma fábrica da CelluForce ${ }^{\mathrm{TM}}$ Inc., o tamanho das partículas logo se tornará um parâmetro de controle de qualidade tendo em vista uma possível legislação regulatória no futuro. Além disso, os pesquisadores também indicam a necessidade de os whiskers estarem bem dispersos na matriz em que serão colocados para a síntese de compósitos e, entre outros fatores, o tamanho da carga influenciará na dispersão.

Outro exemplo do destaque do tamanho do substrato na síntese de compósitos pode ser citado o trabalho de Napolitano et al. (2004), no qual foi estudada a influência do tamanho de partículas de celulose II nas propriedades de compósitos com diferentes tipos de borrachas. Os autores destacaram a importância da morfologia das cargas nas propriedades mecânicas dos elastômeros reforçando-as. Nessa pesquisa, as formas em que a celulose II foi moída determinaram o desempenho mecânico do compósito (tensão e alongamento de ruptura, dureza, resistência ao rasgo e parâmetros reológicos). Mas podem-se imaginar situações que a centrifugação ou outra etapa poderiam ser importantes para a seleção de tamanhos de NCC, tendo como resultado melhor dispersão da carga nanocelulósica numa matriz e atingir-se melhora nas características desejadas.

\subsection{Caracterização das Dimensões dos Nanocristais por Espalhamento Dinâmico de Luz}

Existem várias técnicas que podem medir as dimensões de partículas nanométricas, dentre elas, as mais utilizadas são as microscopias eletrônica de transmissão e de varredura e a de força atômica, e o espalhamento dinâmico de luz. A MET é uma técnica que permite caracterizar a morfologia, a cristalografia e a composição química de nanomateriais. Zanchet et al. (2000) caracterizaram amostras de ouro com tiol, em três proporções, com o uso desta técnica e obtiveram a distribuição de tamanho das partículas para cada reação.

A técnica de Espalhamento Dinâmico de Luz (do inglês Dynamic Light Scattering, ou DLS) também chamada de Espectroscopia de Correlação de Fótons (Photon Correlation Spectroscopy, ou PCS) é amplamente utilizada para determinar a distribuição de tamanhos de nanoestruturas em suspensão. Uma outra técnica utilizada nesse tipo de análise, a espectroscopia no UV-Vis, consiste na absorção ou emissão de radiação eletromagnética decorrente da mudança de estado eletrônico de um elétron numa molécula. Casanova (2010) estudou através de DLS e UV-Vis a estabilidade de nanopartículas de ouro estabilizadas com 
polieletrólitos e tióis.

O equipamento utilizado para o espalhamento de luz (ver, por exemplo, Berne e Pecora, 2000), consiste em um laser que passa por um polarizador, o qual define a polarização do feixe incidente, que incide em uma solução de partículas em movimento browniano, espalhando a luz que, por sua vez, passa por um analisador que seleciona uma dada polarização e, finalmente, entra em um detector, cuja posição define o ângulo $\theta$ de espalhamento, conforme pode ser visto na Figura 1 adaptada de Rodembusch (2001).

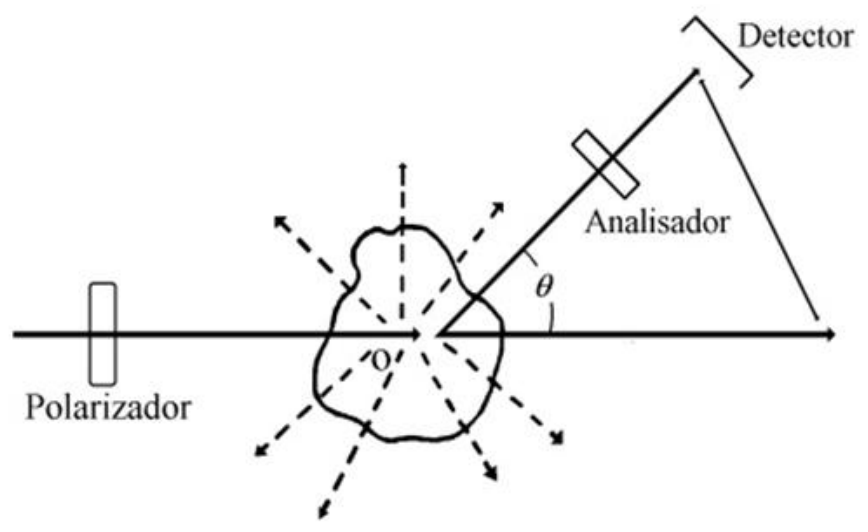

Figura 1: Representação do espalhamento de luz.

Faz parte do aparelho de DLS um correlacionador que calcula a função de correlação da intensidade de luz espalhada, $G^{(2)}(\tau)$, de acordo com a Equação 1.

$$
G^{(2)}(\tau) \equiv\langle I(t) \cdot I(t+\tau)\rangle
$$

Em que, $I(t)$ é um sinal que depende do tempo, $\tau$ é o tempo de retardamento e os colchetes angulares $\langle\ldots\rangle$ representam o valor de média de ensemble do conjunto.

A partir das medidas da função de auto-correlação da intensidade de luz espalhada é possível calcular a função de correlação normalizada $\left(g^{(2)}(\tau)=G^{(2)}(\tau) /\langle I\rangle^{2}\right)$ e a função de correlação normalizada do campo elétrico espalhado, $g^{(1)}(\tau)$. Essas duas últimas se relacionam de acordo com a Equação 2.

$$
g^{(2)}(\tau)=1+\beta\left|g^{(1)}(\tau)\right|^{2}=1+\beta \exp (-2 \Gamma \tau)
$$

Em que, $\beta$ é o fator de correção que depende da geometria e do alinhamento do feixe de laser; $\Gamma$ é a taxa de decaimento da exponencial com $\Gamma=D q^{2}$, onde $\mathrm{D}$ é o coeficiente de 
difusão da partícula, e $q$ é o vetor de espalhamento descrito pela Equação 3.

$$
q=\frac{4 \pi n}{\lambda} \operatorname{sen} \frac{\theta}{2}
$$

Em que, $n$ é o índice de refração da suspensão, $\lambda$ é o comprimento de onda da luz e $\theta$ é o ângulo entre a direção inicial do feixe de luz e o detector.

O espalhamento dinâmico de luz apresenta várias vantagens tais como curta duração do experimento, possibilidade de analisar amostras contendo amplas distribuições de espécies de massas moleculares muito diferentes e é capaz de detectar quantidades muito pequenas de massa, além de ser possível obter medições de diversos parâmetros de interesse, como o peso molecular, o raio de giro e a constante de difusão de translação. A técnica é facilmente utilizada para caracterizar partículas quanto à sua dimensão, principalmente, quando as mesmas são esféricas, visto que partículas não esféricas são medidas em todas as orientações e, portanto, ocasiona um alargamento na distribuição de tamanhos.

Para partículas esféricas monodispersas e diluídas, utiliza-se a lei de Stokes-Einstein para o cálculo de seu diâmetro hidrodinâmico a partir do seu coeficiente de difusão. Apesar de a lei de Stokes ser válida para partículas esféricas, ela pode ser usada para partículas não esféricas, desde que, a razão entre o diâmetro máximo e mínimo não exceda a 4 . Para utilização da técnica em partículas não esféricas, aplicam-se então correlações empíricas (PARIN, 2003). Para caracterização de partículas de tamanhos não regulares, utilizam-se diâmetros de esferas equivalentes às mesmas, com propriedades físicas e geométricas semelhantes (ALLEN, 2007).

A técnica de Espalhamento Dinâmico da Luz Depolarizada (DDLS) é empregada quando se deseja medir dimensões de partículas com estruturas alongadas. Na maioria dos casos, a luz incidente é polarizada na direção perpendicular ao plano de espalhamento. Quando há estruturas alongadas em suspensão, a luz espalhada possui tanto uma componente vertical quanto uma horizontal. (SOUZA LIMA et al., 2003). A movimentação e a rotação das partículas geram essa flutuação na intensidade de luz espalhada. Assim, na análise DDLS utiliza-se um polarizador horizontal adiante do detector, podendo-se medir tanto o coeficiente de difusão translacional como o rotacional dos corpúsculos suspensos, o que é caracterizado pela alteração da função de auto-correlação de dispersão dinâmica da luz.

Neste trabalho, objetivou-se medir o comprimento $(L)$ e a largura $(d)$ de nanocristais de celulose purificados com diferentes forças $G$ de centrifugação usando a técnica de espalhamento dinâmico de luz (DLS). Obtiveram-se as curvas das dimensões dos nanocristais e analisou-se a tendência entre esses parâmetros e a força $G$.

\section{EXPERIMENTAL}

Neste trabalho, amostras de suspensões aquosas de nanocristais de celulose de fibras de algodão provenientes da etapa de suspensão/purificação passaram por centrifugação em cinco diferentes níveis de força $\mathrm{G}: 1840,4140,7370,11510$ e 16580, equivalentes às rotações 4000, 
6000, 8000, 10000 e $12000 \mathrm{rpm}$. Para esta etapa, foi utilizada uma centrífuga Hermle refrigerada modelo Z326K.

As condições utilizadas na etapa de hidrólise das fibras de algodão seguiram metodologia descrita em Carvalho et al. (2012). Basicamente, as fibras de algodão foram submetidas à hidrólise com ácido sulfúrico $65 \%(\mathrm{~m} / \mathrm{v})$, a $50^{\circ} \mathrm{C}$, por 50 minutos e relação de ácido e material celulósico $13 \mathrm{~mL} \mathrm{~g}^{-1}$, sob agitação constante. Após esse período, a hidrólise foi paralisada em erlenmyer contendo gelo e água destilada, no total de $300 \mathrm{~g}$. A etapa de suspensão/purificação para todo o volume foi feita inicialmente para a rotação de $4.000 \mathrm{rpm}$. Para avaliar o efeito da força centrífuga nas dimensões dos nanocristais de celulose, objetivo deste trabalho, o volume da suspensão de nanocristais de aproximadamente $250 \mathrm{~mL}$, foi dividido em cinco porções. Para cada porção foi aplicada a força $G$ especificada neste trabalho no total de cinco, a partir das seguintes frequências de rotação: 4000, 6000, 8000, 10000 e $12000 \mathrm{rpm}$. As suspensões foram acondicionadas em frascos de polipropileno de 100 $\mathrm{mL}$. Todas as centrifugações foram realizadas no tempo de 15 min e temperatura de $23{ }^{\circ} \mathrm{C}$. Foram realizadas duas repetições.

As medidas de espalhamento de luz foram feitas utilizando-se equipamento de espalhamentos estático e dinâmico de luz multiangular da Brookhaven Co. (EUA) que inclui laser de He-Ne com comprimento de onda 632,8 nm (Melles-Griot). Foram realizadas leituras em diferentes posições. Primeiramente, a luz foi polarizada na direção vertical ao sair da fonte e a radiação espalhada foi novamente polarizada nessa direção (ensaios na geometria VV). Para este primeiro caso, o ângulo de medição foi variado de $30^{\circ}$ até $110^{\circ}$. Uma segunda série de experimentos foi realizada alterando-se a polarização da luz espalhada para a direção horizontal (ensaio na geometria $\mathrm{VH}$ ). Nesta segunda sequência, a variação dos ângulos foi de $30^{\circ}$ até $90^{\circ}$.

Antes de qualquer conjunto de análises, para cada suspenção advinda de uma força $\mathrm{G}$ de centrifugação singular, a amostra foi submetida ao processo de filtração com um filtro de $0,2 \mu \mathrm{m}$ de abertura e, em seguida, a suspensão passou por uma etapa de ressonância em um equipamento de ultrassom por 10 minutos. Durante todo o processo, a temperatura foi fixada em $23{ }^{\circ} \mathrm{C}$ com erro de $\pm 0,5^{\circ} \mathrm{C}$.

A seguir, durante a discussão, será detalhado o procedimento realizado para a obtenção das curvas de auto-correlação, o método de obtenção das difusividades e dos coeficientes de difusão e as equações usadas para estimar as dimensões dos NCC.

\section{RESULTADOS E DISCUSSÃO}

De acordo com a literatura, as partículas de NCC possuem forma de acículas com elevada razão de aspecto. Trabalhos como os de Souza Lima et al. (2003), Rosa (2012), Leng (2016), Silva e D’Almeida (2009) e Kaushik et al. (2015) apresentam tabelas e fotomicrografias que corroboram essa geometria com comprimentos variando entre 50 e $1160 \mathrm{~nm}$ e largura entre 3 e $50 \mathrm{~nm}$. Tomando essa premissa como verdadeira, buscou-se através da análise de DLS a obtenção de coeficientes de difusão translacionais $\left(D_{T}\right)$ e coeficientes de difusão rotacionais $(\Theta)$, sendo estes últimos determinados pela análise da 
componente da luz espalhada na polarização horizontal (DDLS). Tais parâmetros foram utilizados para estimar os comprimentos e as larguras dos NCC de fibras de algodão.

Para cada uma das forças $\mathrm{G}$ utilizadas na centrífuga, foram medidas as funções de autocorrelação para os ângulos de $30^{\circ}, 50^{\circ}, 70^{\circ}, 90^{\circ}, 110^{\circ}$ e $130^{\circ}$ usando luz polarizada,medidas que correspondem aos ensaios na geometria VV, e para os ângulos $30^{\circ}, 40^{\circ}, 50^{\circ}, 60^{\circ} 70^{\circ} \mathrm{e}$ $90^{\circ}$ usando luz despolarizada, que correspondem aos ensaios na geometria VH. Na Figura 2 estão apresentados resultados típicos com as curvas de correlação para as geometrias VV e VH para a suspensão de NCC obtida com a força G de 1840 como exemplo. Nesta figura, as linhas contínuas apresentam as curvas resultantes dos ajustes dos dados em cada um dos ângulos. A Equação 4 foi utilizada para o arranjo dos dados da função de auto-correlação VV e a Equação 5 para a VH. Antes dos dados na geometria VH serem tratados, foi necessário fazer uma correção empírica nos pontos de tempos baixos, devido aos efeitos de contagens em excesso de pulsos no detector conhecidos como after pulsing, subtraindo a função de correlação das amostras pela função de correlação medida para um líquido puro, no caso, tolueno.
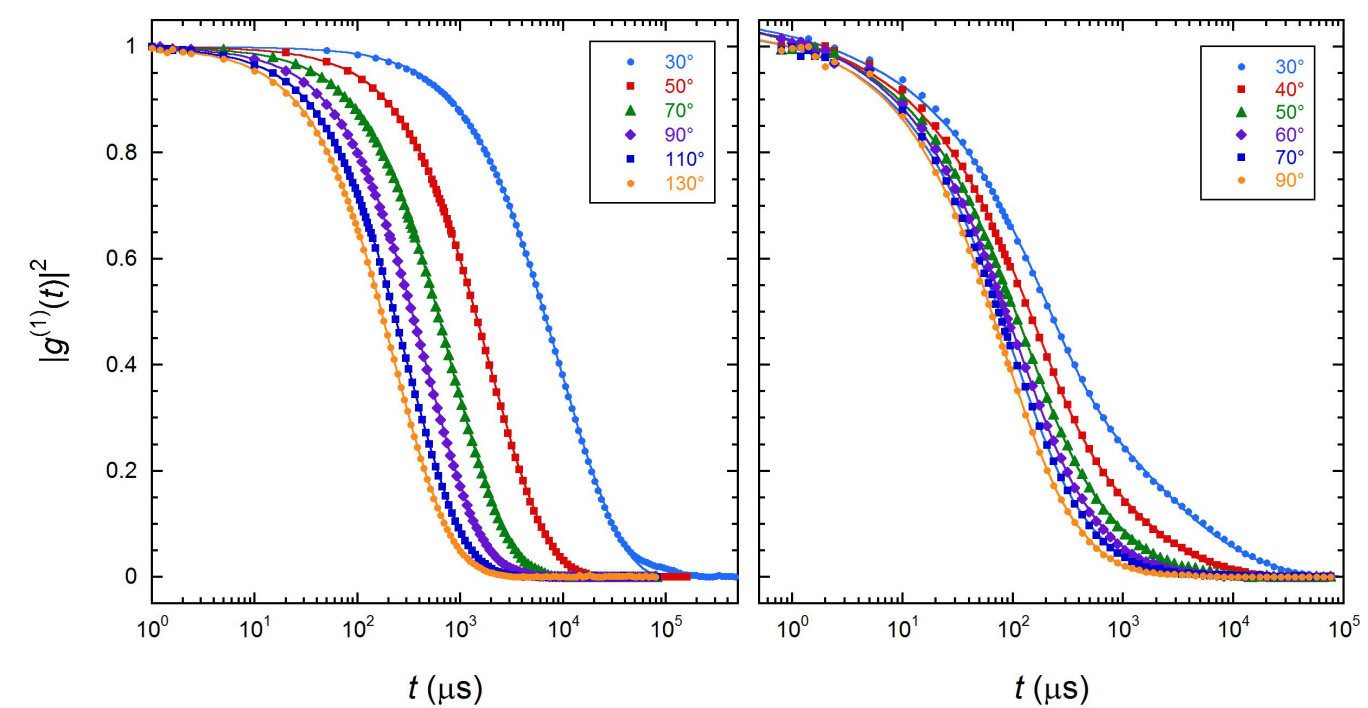

Figura 2: Função de auto-correlação de intensidade de luz espalhada para a força G de 1840 na geometria VV (esquerda) e VH (direita). As linhas contínuas representam as funções ajustadas de acordo com as Equações 4 (esquerda) e 5 (direita).

Um conjunto de hipóteses teóricas e empíricas foi testado para identificar qual modelo melhor acomodaria as séries de dados das curvas de correlação. Deste grupo de pressupostos, foram utilizadas as referências por exponencial simples, exponencial dupla, distribuição contínua de tamanhos usando o programa SEDFIT - algoritmo NNLS e cumulantes. A partir da análise da soma dos quadrados dos erros, na geometria VV, a exponencial dupla (Equação 4) foi o modelo que melhor se ajustou aos dados. No caso da geometria VH, o modelo que melhor explicou os resultados da curva de auto-correlação foi a exponencial alongada, ou o modelo de Williams-Watts (Equação 5). Neste último, à exponencial dupla foi adicionando 
um expoente $v$ ao termo mais lento (menor $\Gamma$ ) e isso é normalmente empregado em sistemas com alto grau de polidispersão de valores.

$$
\begin{aligned}
& g^{(2)}(\tau)-1=\beta\left(A_{1} \exp \left[-\Gamma_{1} \tau\right]+A_{2} \exp \left[-\Gamma_{2} \tau\right]\right)^{2} \\
& g^{(2)}(\tau)-1=\beta\left\{A_{1} \exp \left[-\Gamma_{1} \tau\right]+A_{2} \exp \left[-\left(\Gamma_{2} \tau\right)^{\nu}\right]\right\}^{2}
\end{aligned}
$$
$+A_{2}=1$.

Em que, $A_{1}$ e $A_{2}$ são as amplitudes de cada tamanho de partícula, com a restrição que $A_{1}$

Com os valores de $\Gamma$ determinados, pôde-se obter os coeficientes de difusão translacional $\left(D_{T}\right)$ e os coeficientes de difusão rotacional $(\Theta)$ para cada frequência de centrifugação. O coeficiente de difusão translacional obtido por espalhamento de luz é o mesmo coeficiente de difusão usual encontrado em fenômenos de transferência de massa e definido na primeira lei de Fick (CUSSLER, 2009). Na interpretação molecular ele é definido como um sexto do coeficiente de proporcionalidade do deslocamento quadrático médio de partículas realizando uma caminhada aleatória com o tempo. O coeficiente rotacional, por sua vez, tem definição análoga, porém o deslocamento considerado é angular (DOI \& EDWARDS, 1986). Não há interpretação macroscópica para o coeficiente de difusão rotacional.

$D_{T}$ e $\Theta$ foram obtidos por regressão linear em gráficos de $\Gamma \times q^{2}$, onde $q$ é o modo do vetor de espalhamento relativo a cada ângulo experimental. Em curvas de $\Gamma \times q^{2}$ na geometria $\mathrm{VV}$, a inclinação da reta é o valor de $D_{T}$, Equação 6. Já em gráficos de $\Gamma$ x $q^{2}$ na geometria $\mathrm{VH}$, a inclinação continua sendo o $D_{T}$ bem como o coeficiente linear é igual a $6 \Theta$, Equação 7 (BROERSMA, 1981).

$$
\begin{aligned}
& \Gamma=D_{T} q^{2} \\
& \Gamma=D_{T} q^{2}+6 \Theta
\end{aligned}
$$

A Figura 3 mostra o resultado dos valores obtidos para o decaimento rápido (maior valor de $\Gamma$ ). Para o prosseguimento dos cálculos, o valor de $D_{T}$ considerado foi o resultante da geometria $\mathrm{VV}$, pois para essas curvas foram obtidos melhores coeficientes de determinação $\left(R^{2}\right)$, fornecendo assim resultados mais confiáveis.

A importância da obtenção dos valores dos coeficientes de difusão translacional e rotacional justifica-se por ser possível determinar, a partir da resolução das Equações (8 a 13), o comprimento, $L$, e largura, $d$, médios de estruturas alongadas (BROERSMA, 1981). Os resultados para todos os experimentos estão apresentados na Tabela 3. 


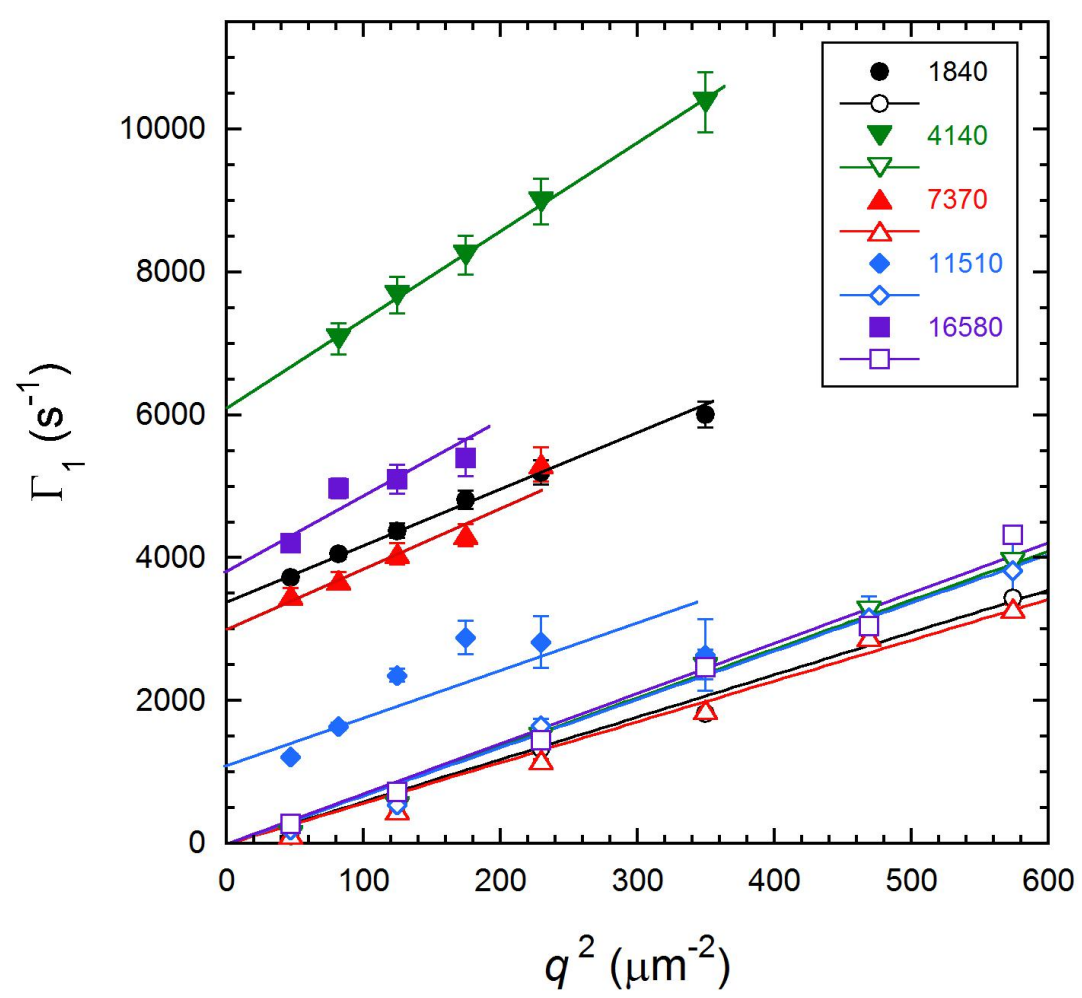

Figura 3: $\Gamma \mathrm{x} q^{2}$ para todas as forças $\mathrm{G}$ aplicadas. Os símbolos vazados indicam os resultados pela geometria VV. Os símbolos preenchidos pela geometria $\mathrm{VH}$.

A Tabela 2 exibe os resultados finais obtidos de $D_{T}$ e $\Theta$ para todos os experimentos.

Tabela 2: Valores dos coeficientes de difusão translacional e rotacional.

\begin{tabular}{ccc}
\hline Força $\mathbf{G}$ & $\boldsymbol{D}_{\boldsymbol{T}}\left(\mathbf{1 0}^{-\mathbf{8}} \mathbf{c m}^{\mathbf{2}} \mathbf{s}^{\mathbf{- 1}}\right)$ & $\boldsymbol{\Theta}\left(\mathbf{s}^{\mathbf{- 1}}\right)$ \\
\hline 1840 & $5,93 \pm 0,19$ & $566 \pm 12$ \\
\hline 4140 & $6,83 \pm 0,21$ & $1013 \pm 47$ \\
\hline 7370 & $5,71 \pm 0,21$ & $504 \pm 21$ \\
\hline 11510 & $6,75 \pm 0,20$ & $566 \pm 11$ \\
\hline 16580 & $7,04 \pm 0,23$ & $634 \pm 25$ \\
\hline
\end{tabular}

$D_{T}=\frac{k_{B} T}{3 \pi \eta L}\left[\delta-\frac{\gamma_{\|}+\gamma_{\perp}}{2}\right]$ 


$$
\begin{aligned}
& \Theta=\frac{3 k_{B} T}{\pi \eta L^{3}}[\delta-\xi] \\
& \delta=\ln \frac{2 L}{d} \\
& \xi=1.14+\frac{0.2}{\delta}+\frac{16}{\delta^{2}}-\frac{63}{\delta^{3}}+\frac{62}{\delta^{4}} \\
& \gamma_{\|}=0.807+\frac{0.15}{\delta}+\frac{13.5}{\delta^{2}}-\frac{37}{\delta^{3}}+\frac{22}{\delta^{4}} \\
& \gamma_{\perp}=-0.193+\frac{0.15}{\delta}+\frac{8.1}{\delta^{2}}-\frac{18}{\delta^{3}}+\frac{9}{\delta^{4}}
\end{aligned}
$$

Em que, $k_{B}$ é a constante de Boltzmann, $T$ é a temperatura da suspensão e $\eta$ é a viscosidade dinâmica da suspensão.

Tabela 3: Valores calculados dos comprimentos $(L)$ e larguras $(d)$ dos nanocristais de celulose de fibras de algodão para cada força $\mathrm{G}$ de centrifugação.

\begin{tabular}{ccc}
\hline Força G & $\boldsymbol{L}(\mathbf{n m})$ & $\boldsymbol{d}(\mathbf{n m})$ \\
\hline 1840 & $268 \pm 10$ & $9,2 \pm 1,5$ \\
\hline 4140 & $213 \pm 10$ & $9,5 \pm 1,5$ \\
\hline 7370 & $279 \pm 14$ & $9,5 \pm 2,0$ \\
\hline 11510 & $294 \pm 14$ & $4,6 \pm 1,2$ \\
\hline 16580 & $283 \pm 9$ & $4,4 \pm 1,2$ \\
\hline
\end{tabular}

Os valores de $L$ encontrados estão na faixa de $213 \pm 10$ a $294 \pm 14 \mathrm{~nm}$, concordando com os medidos para NCC de fibras de algodão por Souza Lima e Borsali (2004) e Heux, Chauve e Bonini (2000), Tabela 1, enquanto as dimensões de $d$ estão entre 4,4 $\pm 1,2$ a 9,5 \pm $2,0 \mathrm{~nm}$, valores, por sua vez, igualmente próximos, porém menores, aos dos trabalhos de Arakie Kuga (2001) e Miller e Donald (2003), também para o mesmo material de partida, Tabela 1. A razão de aspecto dos NCC variou de 22,4 a 66,3, valores esses que indicam melhoras na capacidade de reforço dos NCC numa aplicação de síntese de compósitos (AZEREDO et al. 2009), mas bem maiores que os 9 a 12 encontrados por Bai et al. (2009).

Comparou-se as dimensões dos nanocristais de celulose com as diferentes forças $\mathrm{G}$ de centrifugação. A Figura 4 foi usada como base para essa análise e para determinar se a força 
G utilizada durante a centrifugação seleciona ou não os tamanhos das partículas de NCC de fibras de algodão.

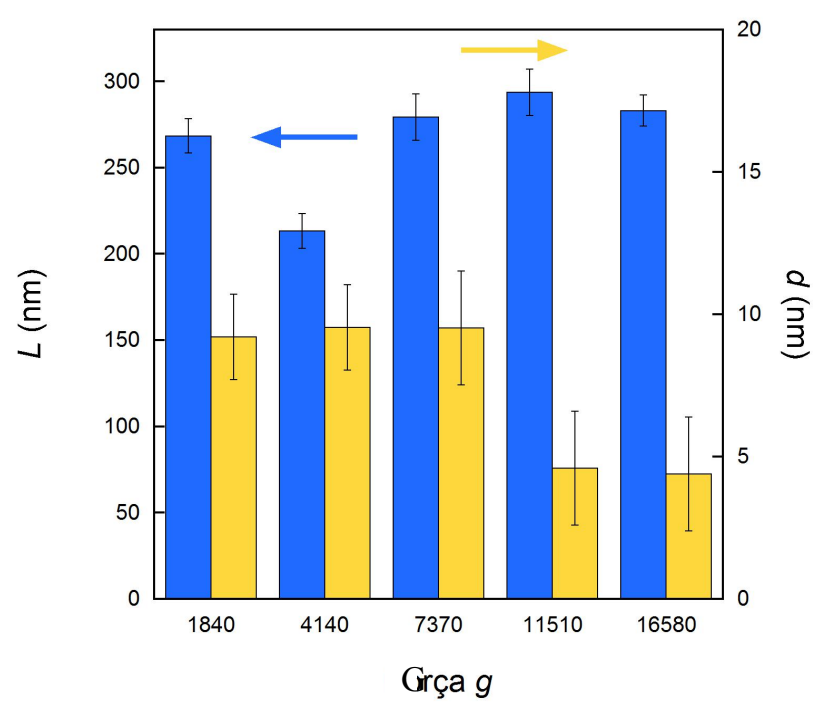

Figura 4: Comprimentos e larguras encontradas dos nanocristais de celulose de algodão em função da força $G$ aplicada pela centrífuga.

O parâmetro força $\mathrm{G}$ dá uma ideia de quantas vezes a força centrípeta, que é exercida sobre os NCC, é maior que a força da gravidade. Quanto maior for esse valor, teoricamente, menores serão as massas dos NCC que estarão em suspensão, pois, os mais pesados tenderiam à sedimentar.

Considerando que todos os NCC de fibras de algodão têm a mesma massa específica, a variação das massas dessas nanopartículas em relação à largura será maior que a mesma em relação ao comprimento, já que o volume de um NCC em forma de acícula está relacionado com a largura elevada à segunda potência. Isto é, variações na largura tem mais efeito na alteração da massa da partícula do que mudanças no comprimento.

Primeiramente, tendo como base os valores médios de largura e comprimento, pode-se concluir que o aumento da força $G$ aplicada no processo de purificação resulta em uma solução na qual os NCC em suspensão apresentam larguras menores, enquanto não se nota mudança significativa no comprimento dos mesmos, nesta faixa de força $G$ aplicada. Isso é um resultado que vai de encontro ao medido por Bai et al. (2009). Para estes autores, o diâmetro teve pouca variação, mas os comprimentos diminuíam com o aumento da força $\mathrm{G}$. Lembrando que a faixa de força $G$ empregada no estudo de Bai et al.(2009) foi com valores menores (195 à 2383 de força $G$ ) que os utilizados no presente estudo.

Nota-se que de 7370 para 11510 de força G, a largura cai pela metade (Figura 4). Entretanto, deve-se enfatizar que os valores de $\Gamma$ x q $\mathrm{q}^{2}$ para os valores maiores de força $\mathrm{G}$ apresentaram maior desvio em relação à linearidade (menores $\mathrm{R}^{2}$ ), fornecendo assim valores de coeficientes de difusão com maior incerteza. Tendo em vista as potenciais aplicações comerciais, poderiam ser evitados gastos desnecessários de energia ou de 
superdimensionamento da centrífuga, caso a fase de centrifugação dos nanocristais de celulose de algodão impossibilitar a seleção dos tamanhos.

\section{CONCLUSÃO}

Este trabalho teve como objetivo principal verificar o efeito da força $\mathrm{G}$ nas dimensões de nanocristais de celulose de fibras de algodão obtidos a partir da hidrólise com ácido sulfúrico $65 \% \mathrm{~m} / \mathrm{v}$. Os valores de $L$ e $d$ encontraram-se nas faixas de $213 \pm 10$ a $294 \pm 14 \mathrm{~nm}$ e $4,4 \pm 1,2$ a $9,5 \pm 2,0 \mathrm{~nm}$, respectivamente. Os resultados concordaram com os disponíveis na literatura, confirmando assim a aplicabilidade da técnica de DDLS para o estudo da dinâmica dos NCC em suspensões aquosas. Ainda com base nestes resultados, não pôde ser observada variação significativa do comprimento $(L)$ dos NCC em suspensão com aumento da força $G$ dentro da faixa estudada. No entanto, para a largura (d), pôde se observar que houve diminuição do seu valor médio a partir do valor de 7370 de força G. Para aplicação dos NCC, será necessário um estudo para averiguar qual diferença mínima no diâmetro dos NCC seria suficiente para influenciar nas propriedades do compósito final. Já que realizando centrifugações com forças $G$ de 1840 a 16580 nota-se uma amplitude de 4,4 a 9,5 nm nas larguras dos nanocristais. Se esta extensão não gera modificações na propriedade desejada, podem-se evitar gastos energéticos utilizando centrífugas menos robustas no processo de purificação dos NCC.

\section{REFERÊNCIAS}

ALLEN, T. Particle size measurement. Volume 1: Powder sapling and particle size measurement. London: Chapman \& Hall. 1997. 5th ed. 525 p.

ARAKI, J.; KUGA, S. Effect of trace electrolyte on liquid crystal type of cellulose microcrystals.Langmuir, v. 17, p. 4493-4496, 2001.

BAI, W.; HOLBERY, J.; KAICHANG, L. I. A technique for production of nanocrystalline cellulose with a narrow size distribution. Cellulose, v. 16, n. 3, p. 455-465, 2009.

BERNE, B. J.; PECORA, R. Dynamic Light Scattering: with applications to Chemistry, Biology, and Physics; John Wiley \& Sons, Inc., New York, 2000.

BROERSMA, S. Viscous force and torque constants for a cylinder. The Journal of Chemical Physics, v. 74, p. 6989, 1981.

CARVAlHO, E. G. L.; Neves, M. T.; Vieira, A. P. B.; Silva, D. J.; Almeida, J. M.; Rodrigues, F. A. Isolamento de nanocristais de celulose de diferentes materiais celulósicos. In: $45^{\circ}$ Congresso e Exposição Internacional de Celulose e Papel, São Paulo. $45^{\circ}$ ABTCP (CD), 2012.

CASANOVA, M. C. R. Síntese, caracterização e estudo da estabilidade de nanopartículas metálicas estabilizadas com polieletrólitos e tióis. 86 p. Tese. Universidade de São Paulo, Instituto de Química de São Carlos, 2010. 
CUSSLER, E. L. Diffusion: Mass Transfer in Fluid Systems. $3^{\text {a }}$ ed. Cambridge: Cambridge University Press, 2009.

DOI, M.; EDWARDS, S. F. The Theory of Polymer Dynamics. Oxford: Clarendon Press, 1986.

DONG, X. M.; KIMURA, T.; REVOL, J. F.; GRAY, D. G. Effects of ionic strength on the isotropic-chiral nematic phase transition of suspensions of cellulose crystallites. Langmuir, v. 12, n. 8, p. 2076, 1996.

ELAZZOUZI-HAFRAOUI, S.; NISHIYAMA, Y. P. J. L.; HEUX L.; DUBREUIL F.; ROCHAS, C. The Shape and Size Distribution of Crystalline Nanoparticles Prepared by Acid Hydrolysis of Native Cellulose. Biomacromolecules, v.9, p. 57-65, 2008.

FRASCHINI, C.; CHAUVE, G.; LE BERRE, J-F.; ELLIS, S.; Méthot, M.; O’Connor, B.; Bouchard, J. Critical discussion of light scattering and microscopy techniques for CNC particle sizing. Nordic Pulp \& Paper Research Journal, v. 29, n. 1, p. 31-40, 2014.

HENRIQUE, M. A. Estudo cinético da decomposição térmica de nanocristais de celulose de caroço de manga, eucalipto e celofane. Dissertação. Universidade Federal de Uberlândia, Instituto de Química, Uberlândia, 2014.

HEUX, L.; CHAUVE, G.; BONINI, C. Nonflocculating and Chiral-Nematic Self-ordering of Cellulose Microcrystals Suspensions in Nonpolar Solvents. Langmuir, v. 16, n. 21, p. 8210, 2000.

KAUSHIK, M.; FRASCHINI, C.; CHAUVE, G.; PUTAUX, J.; MOORES, A. Transmission Electron Microscopy for the Characterization of Cellulose Nanocrystals. In: Khan, M. The Transmission Electron Microscope - Theory and Applications. InTech, p. 129$163,2015$.

LENG, T. Cellulose Nanocrystals: Particle Size Distribution and Dispersion in Polymer Composites. Dissertação. Universidade de Ottawa, Canadá, 2016.

MILLER, A. F.; DONALD, A. M.; Imaging of Anisotropic Cellulose Suspensions Using Environmental Scanning Electron Microscopy.Biomacromolecules, v. 4, n. 3, p. 510$517,2003$.

NAPOLITANO, B. A.; MARTINS, A. F.; VISCONDE, L. L. Y.; NUNES, R. C. R. Compósitos de Borracha Natural ou Policloropreno e Celulose II: Influência do Tamanho de Partícula. Polímeros: Ciência e Tecnologia, v. 14, n. 4, p. 223-229, 2004.

NETO, W. P. F. Extração e caracterização de nanocristais de celulose a partir de casca de soja, e sua aplicação como agente de reforço em nanocompósitos poliméricos utilizando carboximetilcelulose como matriz. Dissertação. Universidade Federal de Uberlândia, Instituto de Química, Uberlândia, 2012.

PARIN, C. J. Estudo comparativo de métodos de determinação do tamanho de partícula. Tese. Universidade de São Paulo, 2003.

RODEMBUSCH, F. S. Espalhamento de luz estático e dinâmico em polímeros do tipo polimetacrilato, fluorescentes por transferência protônica intramolecular no estado eletrônico excitado (TPIEE). Dissertação. Universidade Federal do Rio Grande do Sul, Programa de Pós-Graduação em Química, 2001. 
ROSA, S. M. L. The Transmission Electron Microscope - Theory and Applications. Tese. Universidade Federal do Rio Grande do Sul, Porto Alegre, 2012.

SILVA, D. J.; D’ALMEIDA, M. L. O. Nanocristais de Celulose. O Papel. v. 70, n. 7, pp. 34$72,2009$.

SOUZA LIMA, M. M.; BORSALI, R. Rodlike Cellulose Microcrystals: Structure, Properties, and Applications. Macromolecular Rapid Communications, v. 25, n. 7, p. 771-787, 2004.

SOUZA LIMA, M. M.; WONG, J. T.; PAILlET, M.; BORSALI, R.; PERCORA, R. Translational and Rotational Dynamics of Rodlike Cellulose Whiskers. Langmuir, v. 19 n. 1, p. 24-29, 2003.

ZANCHET, D.; TOLENTINO, H.; MARTINS ALVES, M.C.; ALVES, O. L.; UGARTE, D. Inter-atomicdistance in thiol-passivated gold nanoparticles. Chem. Phys. Lett., v. 323, p. $167-172,2000$.

\title{
THE EFFECT OF CENTRIFUGATION STAGE ON CELLULOSE NANOCRYSTALS' SIZE
}

\author{
D. S. SOARES ${ }^{1}$, F. P. MARTINS ${ }^{1}$, G. A. PUIATTI ${ }^{1}$, R. A. AMARAL ${ }^{1}$, R. L. TEMOTEO ${ }^{1}$, T. \\ G. CARMO ${ }^{1}$, V. K. C. GERMANO ${ }^{1}$, D. J. SILVA ${ }^{1}$, A. V. N. C. TEIXEIRA ${ }^{2}$ \\ Universidade Federal de Viçosa, ${ }^{1}$ Departamento de Química \\ ${ }^{2}$ Departamento de Física. \\ E-mail: diego.s.soares@ufv.br
}

\begin{abstract}
The relation between the cellulose nanocrystals (CNC) dynamic properties and the centrifugation $G$ force applied on their purification process was investigated using the depolarized dynamic light scattering technic. Samples containing CNC were prepared using sulfuric acid hydrolysis and centrifugated on the following G forces: 1840, 4140, 7370, 11510 e 16580. The translational and rotational diffusion coefficients were determined for the different samples, from these values, the CNC widths $(d)$ and lengths $(L)$ were calculated. The values for the $d$ and L lied from $213 \pm 10 \mathrm{~nm}$ to $294 \pm 14 \mathrm{~nm}$ and 4,4 $\pm 1,2 \mathrm{~nm}$ to 9,5 \pm 2,0nm, respectively. The results agree with the the literature, confirming the applicability of the technic on the study of NCC dynamic properties in aqueous suspensions. There was no significant variation on the values of $L$ by the increment on the $G$ force within the studied interval. On the other hand, d reduced with the G force increase for values above 7370.
\end{abstract}

KEYWORDS: Cellulose nanocrysrals; Centrifugation; G force; Dynamic light scattering; Nanostructures characterization. 